\title{
Análise de erros na resolução de problemas matemáticos
}

\author{
Error analysis in solving mathematical problems
}

\author{
Geovanna Luiza Kliemann ${ }^{1}$ \\ Maria Madalena Dullius²
}

\section{Resumo}

Apresenta-se neste trabalho, uma pesquisa desenvolvida no âmbito do Programa Observatório da Educação, com o propósito de auxiliar na melhoria da qualidade dos processos de ensino e aprendizagem da Matemática na Educação Básica. A partir do estudo dos sistemas avaliativos que constituem o escopo de investigação do projeto, verificou-se que o foco destes é a resolução de problemas, desenvolveu-se então várias ações com o objetivo de auxiliar os estudantes no processo de resolução dos mesmos. Uma dessas ações objetivou analisar os erros apresentados por estudantes do $5^{\circ}$ ano na interpretação, compreensão e resolução de problemas. Descreve-se três encontros desenvolvidos em seis escolas, com questões retiradas da Prova Brasil realizadas em anos anteriores, com o objetivo de diagnosticar as principais dificuldades apresentadas pelos alunos na resolução dos problemas, além de auxiliálos a verificar possibilidades de superar tais lacunas. Para atingir os objetivos propostos, foi realizado um estudo qualitativo em que os pesquisadores estiveram constantemente envolvidos durante 0 processo. Após cada encontro, realizou-se uma análise das respostas desenvolvidas, classificando os erros cometidos em diferentes categorias. Verificou-se que a maioria dos estudantes atendidos obteve êxito na resolução dos problemas propostos, e os principais erros apresentados estão relacionados à dificuldade de interpretação

Palavras chave: resolução de problemas; matemática; erros.

\section{Abstract}

This paper presents a survey carried out within the Centre for Education Programme, in order to assist in improving the quality of the teaching and learning of Mathematics in Primary Education. From the study of the evaluative systems that constitute the scope of the research project, it was found that their focus is solving problems, and from this point it began the development of several actions with the purpose of assisting the students in the process of solving them. One of these actions objected to analyze the errors presented by students in the 5th year in the interpretation, understanding and problem solving. We describe three games developed in six schools, with questions drawn from the "Prova Brasil" performed in previous years, in objective to diagnose the main difficulties presented by the students in solving the problems, besides helping them to verify possibilities to overcome such gaps. To reach the proposed objectives, a qualitative study was carried out in which the researchers were constantly involved during the process. After each meeting, there was an analysis of the responses developed to classify the errors in different categories. It was found that most students attended succeeded in solving the proposed problems, and major errors presented are related to the difficulty of interpretation.

Keywords: problem solving; mathematics; errors.

\footnotetext{
${ }^{1}$ Secretaria da Educação do Rio Grande do Sul | geovanakliemann@universo.univates.br

${ }^{2}$ Universidade do Vale do Taquari - Univates | madalena@univates.br
} 


\section{Abordagem teórica}

A Matemática no contexto atual é necessária para o convívio em sociedade, além de auxiliar no desenvolvimento intelectual e no raciocínio lógico. Apesar da sua relevância, esta disciplina continua sendo uma área em que os alunos têm baixo aproveitamento e apresentam elevado índice de rejeição. Com isso, os integrantes do projeto Observatório da Educação, intitulado "Relação entre a formação inicial e continuada de professores de Matemática da Educação Básica e as competências e habilidades necessárias para um bom desempenho nas provas de Matemática do SAEB, Prova Brasil, PISA, ENEM e ENADE", desenvolveram ações para melhorar a qualidade de ensino e aprendizagem da Matemática na Educação Básica. Neste trabalho são descritos os resultados de uma ação/investigação desenvolvida no âmbito do projeto.

A investigação teve como problemática a elaboração de uma prática pedagógica centrada nas teorizações do campo da resolução de problemas em turmas de $5^{\circ}$ ano do Ensino Fundamental. Visto o problema de pesquisa, os objetivos direcionaram-se em contribuir com a abordagem da resolução de problemas, bem como verificar quais os principais erros que os alunos cometem ao resolverem problemas matemáticos, e a partir desses rever junto aos alunos as falhas cometidas durante o processo, para reconstruírem seus conhecimentos, além de, socializar diferentes possibilidades apresentadas para resolução.

Onuchic (1999) afirma que a abordagem de Resolução de Problemas pode ser uma metodologia de ensino, em que o aluno aprende Matemática resolvendo problemas como também aprende a Matemática para resolver problemas.

É importante ter a visão de que o entender deve ser o principal objetivo do ensino, apoiados na crença de que o aprendizado de matemática, pelos alunos, é mais forte quando é auto gerado do que quando thes é imposto por um professor ou por um livrotexto. Quando os professores ensinam matemática através de resoluções de problemas, eles estão dando aos seus alunos um meio poderoso e muito importante de desenvolver sua própria concepção. (ONUCHIC, 1999, p. 208)

Ao trabalhar com Resolução de problemas é preciso analisar o processo de resolução e não somente o resultado final. É importante considerar o desenvolvimento que o aluno utilizou para solucionar as questões propostas, percebendo as estratégias, detectando dificuldades e buscando alternativas para superar as dificuldades apresentadas, e isso é possível a partir dos erros cometidos pelos alunos. Dessa forma, a análise de erros é uma ferramenta significativa para a aprendizagem, possibilitando ao professor fazer seu planejamento a partir de aspectos que necessitem de maior ênfase, explorando os erros para superar dificuldades apresentadas pelos alunos.

Smole e Diniz (2001, p. 139) enfatizam que "[...] quando os alunos são incentivados a expressar livremente seu modo de pensar, é natural que surjam algumas soluções incorretas". A partir deste raciocínio o professor pode discutir com os alunos os erros cometidos, e assim o aluno pode identificar, rever e organizar uma nova solução de forma adequada.

Os Parâmetros Curriculares Nacionais PCN de Matemática (2002) também abordam a importância de trabalhar resolução de problemas e observar aos erros cometidos pelos alunos durante o processo, considerando algo significativo na construção de seus conhecimentos. 
Não somente em Matemática, mas até particularmente nessa disciplina, a resolução de problemas é uma importante estratégia de ensino. Os alunos, confrontados com situaçõesproblema, novas, mas compatíveis com os instrumentos que já possuem ou que possam adquirir no processo, aprendem a desenvolver estratégia de enfrentamento, planejando etapas, estabelecendo relações, verificando regularidades, fazendo uso dos próprios erros cometidos para buscar novas alternativas; adquirem espírito de pesquisa, aprendendo a consultar, a experimentar, a organizar dados, a sistematizar resultados, a validar soluções; desenvolvem sua capacidade de raciocínio, adquirem auto-confiança e sentido de responsabilidade; e, finalmente, ampliam sua autonomia e capacidade de comunicação e de argumentação. (BRASIL, 2002, p. 52)

Para Cury (2008), os erros cometidos pelos alunos são oportunidades que o sujeito tem de reconstruir seu próprio conhecimento. O erro é elemento importante para a aprendizagem, uma vez que a evolução da inteligência e dos conhecimentos provém de situações perturbadoras.

Não há processo de conhecimento sem erro. O erro é parte constitutiva da aprendizagem e do desenvolvimento cognitivo. Tentar impedir de todas as formas que o aluno erre equivale a obstruir o processo de sucessivas aprendizagens. É o mesmo que impedir que o aluno construa os instrumentos indispensáveis ao seu pensar (CHAVES, 2010, p. 13)

Para Libâneo (1994), grande parte dos alunos apresenta dificuldades na resolução de problemas matemáticos. Isso pode estar relacionado à metodologia utilizada pelos professores, quando a avaliação é predominantemente em forma de "prova", e ao final de um período os alunos testam seus conhecimentos. O autor ressalta que o papel da escola é fundamental na formação dos alunos e vai muito além dos conteúdos didáticos transmitidos, pois as atitudes do dia a dia influenciam na afetividade, na segurança e no desenvolvimento da autonomia. O conhecimento deve ser entendido como algo que se constrói, e o erro deve ser visto como um elemento potencial, pois é preciso respeitar as diferenças dos educandos que aprendem de forma e ritmo próprio. Segundo os PCN.

[...] o erro faz parte do processo de aprendizagem e pode estar expresso em registros, respostas, argumentações e formulações incompletas do estudante. Desde que consistentemente trabalhado pelo professor, o erro é um elemento que pode permitir ao estudante tomar consciência do seu próprio processo de aprendizagem, da apropriação que faz de diferentes conteúdos, percebendo que há diferenças entre o senso comum e os conceitos científicos e que é necessário saber aplicar diferentes domínios de ideias em diferentes situações (BRASIL, 2002, p. 32).

Neste sentido as ações do professor são fundamentais e devem complementar as necessidades dos alunos, permitindo construir novos conhecimentos, favorecendo sua autonomia e diagnosticando suas reais condições e dificuldades sobre determinados conteúdos para mediar os caminhos a serem seguidos.

Para investigar as dificuldades encontradas e os erros cometidos pelos alunos nos problemas desenvolvidos, é necessário um estudo particular para cada caso, pois habitualmente as resoluções não seguem o mesmo caminho. Assim, é importante "conhecer os limites, a gênese de seus erros, para facilitar o direcionamento do processo de ensino e de aprendizagem [...]. Isso pode estimular a inovar e tentar novos caminhos para o "fazer matemática" em sala de aula" (ALVARENGA, ANDRADE e SANTOS, 2016, p. 51). Para entender a dúvida do aluno, cabe ao professor questioná-lo, pois suas respostas podem 
revelar não apenas sobre o que ele sabe, mas também o que não sabe. Os erros podem estar atribuídos a vários fatores, como distração e à falta de leitura e consequente incompreensão do que lê. Para Silveira

A construção possível de outra linguagem na matemática é um dos problemas que os alunos encontram para responder um questionamento. "Não entendi o enunciado" é um argumento comum na voz dos alunos. Assim, não basta o aluno ter construído todos os conceitos que envolvem um dado problema, é necessário a conexão destes conceitos (SILVEIRA, 2006, p. 3).

Quando essa conexão está falha ou em fase de construção, ocorrem os erros, estes que dão indícios de quais os melhores caminhos a percorrer para potencializar o ensino de modo a facilitar a aprendizagem dos alunos.

\section{Materiais e métodos}

Para atingir os objetivos propostos, foram desenvolvidas intervenções mensais em seis escolas parceiras do Projeto Observatório da Educação com o intuito de desenvolver junto aos alunos que integram as turmas de $5^{\circ}$ ano do Ensino Fundamental dessas escolas 0 gosto pela Matemática, visando contribuir com a abordagem da resolução de problemas matemáticos. Descreve-se aqui as três primeiras intervenções realizadas com esta série. As questões abordadas foram retiradas da matriz curricular das avaliações externas (Prova Brasil e SAEB) de anos anteriores. As atividades propostas nas turmas foram selecionadas com o intuito de auxiliar os alunos na interpretação, compreensão e resolução dos problemas, sendo este o foco principal dessas avaliações.

O desenvolvimento das intervenções foi ministrada pela equipe do Observatório, sendo que a cada encontro dois professores/bolsistas conduziam o desenvolvimento das atividades junto aos alunos, estes deviam justificar de forma escrita a resposta dada a cada questão que resolviam, possibilitando aos pesquisadores identificar não apenas o erro cometido, mas também o que o gerou.

No decorrer dos encontros foram propostos diversos problemas objetivando estimular nos alunos a iniciativa, o espírito explorador, a criatividade e a habilidade de elaborar um raciocínio lógico, para que possam, segundo Dante (1998), propor boas soluções às questões que surgem no seu cotidiano.

No primeiro encontro, além das discussões iniciais, aplicou-se o primeiro conjunto de problemas para os alunos desenvolverem. Ao término deste e dos demais encontros os alunos colavam em seus diários de bordo as atividades realizadas, como meio de organização para posterior análise e correção das resoluções. Estes foram numerados para identificar cada aluno.

Nos encontros seguintes, inicialmente, retomava-se com os alunos os problemas propostos no encontro anterior, em que eram socializadas as diferentes estratégias utilizadas para resolução e se explorava os erros e acertos cometidos, buscando fortalecer a auto confiança dos alunos e a superação de dificuldades, fazendo-os perceber que existem diferentes possibilidades de resolução. E para finalizar, se propunha novos problemas. Assim, para o professor, os erros cometidos na resolução de problemas não deveriam ser considerados apenas do aspecto negativo, "pois é por meio deles que o professor poderá perceber onde seus alunos erram e terá a oportunidade de mostrar que cada um pensa de uma forma" (ALVARENGA, ANDRADE e SANTOS, 2016, p. 44). 
Depois de concluídas as três primeiras intervenções, realizou-se uma análise dos erros apresentados pelos alunos no desenvolvimento dos problemas e elencou-se cinco categorias distintas, descritas no Quadro 1.

Sobrecarga Cognitiva;

Erros na compreensão do enunciado;

Erros por falha em uma etapa do procedimento;

Erros devido a associações incorretas;

Só resposta.

Quadro 1 - Categorias de erros apresentadas pelos alunos envolvidos

1. Sobrecarga Cognitiva: Astolfi (1999) diz que o desenvolvimento cognitivo está relacionado com a forma que o aluno desenvolve o conjunto de estruturas e maneiras de pensar e agir, e se dá através da interação com o meio em que vive. A capacidade cognitiva é a capacidade de pensar, perceber, memorizar e construir estratégias para a resolução de problemas. Para Davis e Espósito (1990 apud Piaget) ela é formada por dois mecanismos que agem simultaneamente: assimilação e a acomodação.

2. Erros de compreensão do enunciado: ocorre quando o aluno seleciona os dados, mas não entende o que, de fato, o problema pede que se faça com os mesmos. $O$ aluno não possui capacidade de interpretar o enunciado dentro do contexto. Entende-se que ele não está habituado a fazer a leitura pelas "entrelinhas" ou seja, decodificar o que realmente está sendo pedido para ser realizado. Faz a leitura de forma rápida sem raciocínio e focam apenas na oralidade e não no teor explicativo do conteúdo.

Para Smole e Diniz (2001), a leitura tem grande importância em qualquer área de conhecimento, a leitura é o principal fator associado aos erros cometidos pelos alunos por não compreenderem o que o enunciado de um problema propõe. É importante que desde cedo o aluno desenvolva o hábito de leitura, para ajudá-lo a compreender as expressões utilizadas pelos livros, os símbolos matemáticos, conceitos e fórmulas, pois é um dos caminhos para ampliar a aprendizagem.

3. Erros por falha em uma etapa: os erros por falha em uma etapa ocorrem porque o aluno, por um descuido, comete um erro no desenvolvimento do problema. Os procedimentos adotados para solucioná-los evidenciam que o aluno possui as habilidades para a resolução, no entanto comete um erro no cálculo. Segundo Dullius et al (2012) os erros nas etapas são atribuídos à falta de cuidado ou distração e acontecem quando o estudante possui conhecimento necessário para desenvolver tais atividades.

4. Associações Incorretas: Radatz (1979) diz que os erros cometidos por associações incorretas podem estar relacionados à falta de flexibilidade do pensamento ou por distração, no qual o aluno aplica qualquer operação a qualquer dado contido no problema para efetuar a resolução.

5. Só resposta: esta categoria foi criada pelas autoras deste artigo, pois várias questões não puderam ser enquadradas nas demais categorias, devido aos alunos não apresentarem o raciocínio utilizado na resolução e apenas marcarem uma das alternativas propostas, uma vez que as questões eram de múltipla escolha. Isso pode estar relacionado com o fato do aluno ter feito algum cálculo mental ou simplesmente ter marcado qualquer alternativa disponível.

Cabe destacar que será descrito, neste estudo, a prática decorrente de três encontros, no entanto, novas intervenções foram desenvolvidas durante todo ano, esperando auxiliar os estudantes nos aspectos em que apresentaram maior dificuldade e proporcionar 
condições de refletirem e compreenderem em que e porque erraram. Portanto, buscou-se a cada encontro retomar os erros cometidos, para que observem o que estava falho e assim vindo a tomar consciência do seu erro. Segundo os PCN, "Os erros dos estudantes também indicam as necessidades de ajustes no planejamento de quem ensina ou no programa da área" (1998, p. 32). A partir da análise dos erros com os alunos é possível auxiliá-los a transformar as dificuldades em aprendizagem.

\section{Discussão}

Nesta etapa, apresenta-se a análise realizada nas questões desenvolvidas com os alunos, traz-se resultados de três intervenções realizadas com 81 alunos do $5^{\circ}$ ano do ensino fundamental de seis escolas estaduais do Vale do Taquari, RS. As questões abordadas e retiradas das avaliações externas foram identificadas por letras e números, sendo no $1^{\circ}$ encontro ( $A 1$ e $A 2$ ), no segundo encontro (B1, B2 e B3) e no terceiro encontro (C1, C2 e C3). As questões foram analisadas e classificadas conforme os erros apresentados pelos alunos, buscando estratégias de ensino para superar suas dificuldades. Assim, descreve-se os resultados dessas intervenções.

A primeira atividade desenvolvida com os alunos teve duas questões norteadoras, que estão descritas na sequência. Nesta analisou-se a resolução dos alunos e apresenta-se, na Figura 1, o raciocínio de um aluno acerca da questão A1.

1) A tabela abaixo mostra a data de nascimento de quatro alunos.

\begin{tabular}{|l|l|l|l|}
\hline \multirow{2}{*}{ Nomes } & \multicolumn{2}{|l|}{ Data de nascimento } & \multicolumn{2}{l|}{} \\
\cline { 2 - 4 } & Dia & Mês & Ano \\
\hline Márcia & 7 & Abril & 1998 \\
\hline Alex & 12 & Abril & 1998 \\
\hline Samuel & 26 & Abril & 1998 \\
\hline Aline & 15 & Abril & 1998 \\
\hline
\end{tabular}

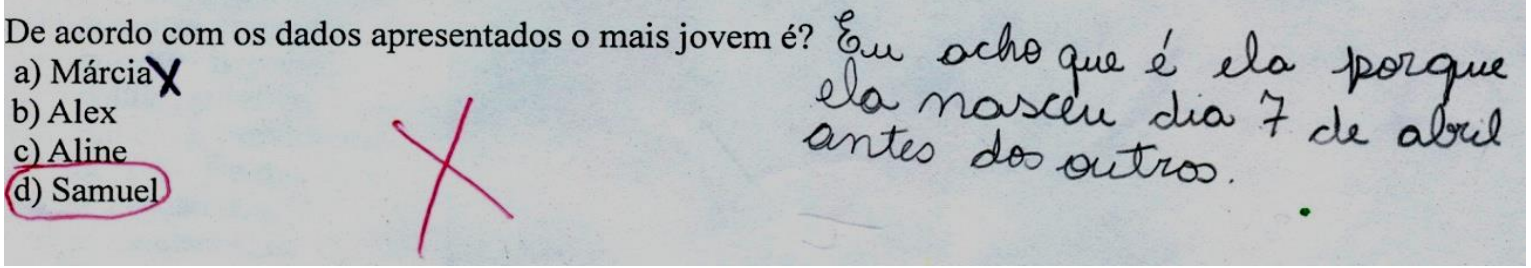

Figura 1: Resolução da Questão A1 apresentada pelo aluno 38

Nesta questão os alunos tiveram alto índice de erros, sendo que vinte e três foram classificados na categoria 1, pois percebeu-se que relacionaram a pessoa mais velha com a data de maior valor numérico. Outros vinte e um alunos marcaram somente uma alternativa, não deixando claro qual foi o raciocínio utilizado para solucionar o problema, sendo incluídos na categoria 5.

O Gráfico 1 representa os acertos e os erros cometidos pelos alunos na questão A1. 


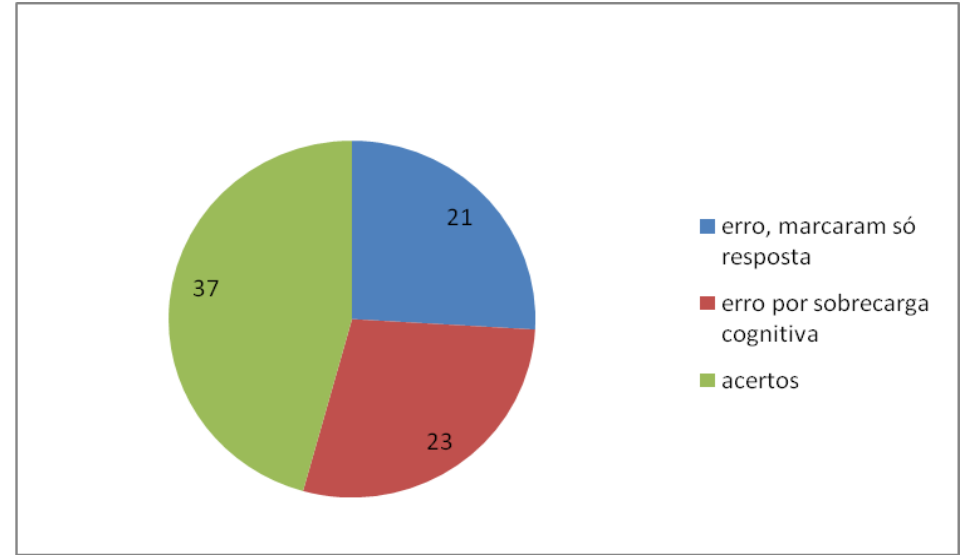

Gráfico 1: Erros e acertos dos alunos para questão A1

Os alunos que se enquadraram nos erros por falta de capacidade cognitiva indicam uma falha que precisa ser trabalhada para permitir melhor desenvolvimento da resolução. Os demais erros cometidos são os que apenas assinalaram uma alternativa, sem apresentar indícios da estratégia utilizada para chegar à resposta.

Na Figura 2, apresenta-se a questão A2 e o raciocínio de um dos alunos.

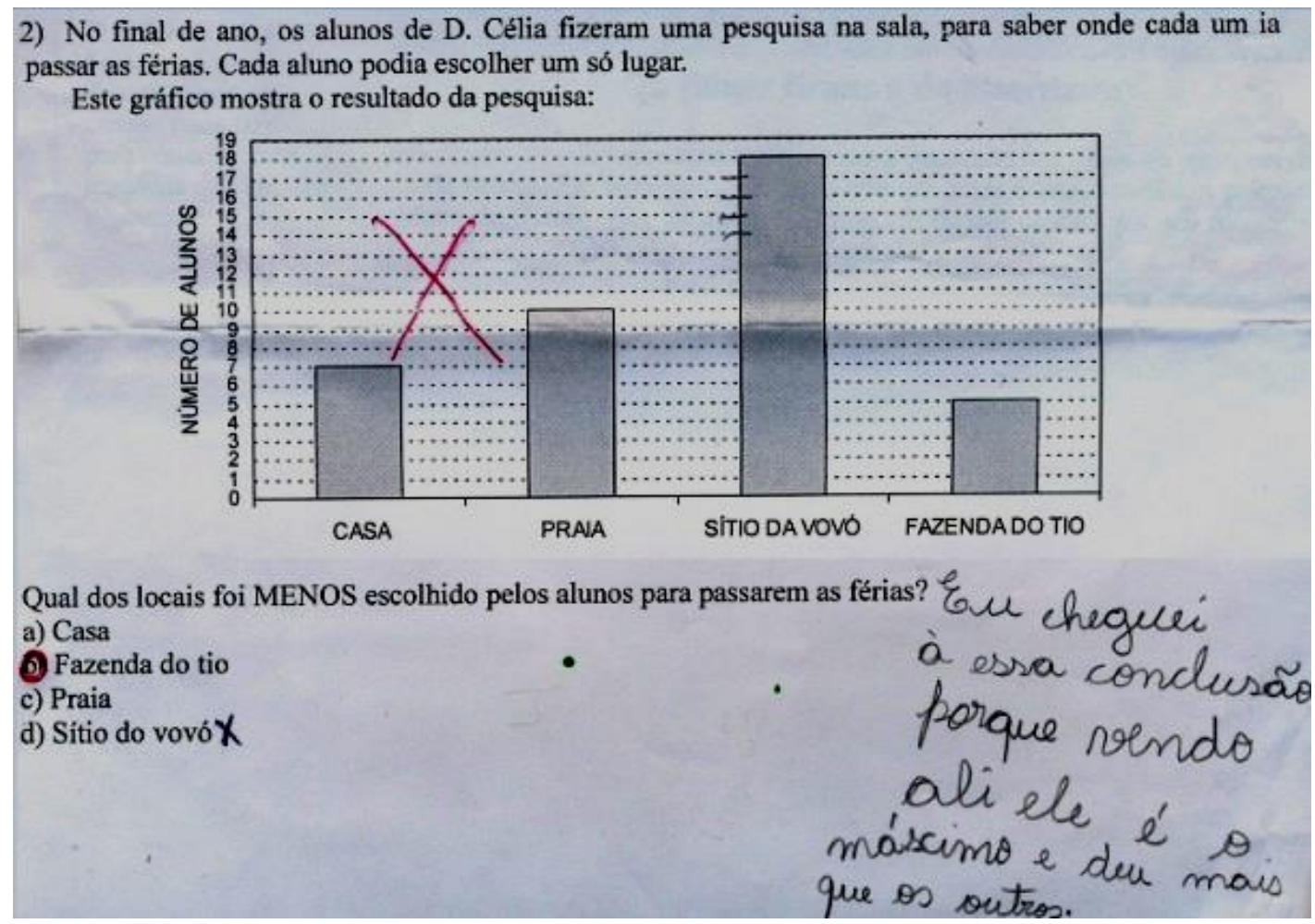

Figura 2: Resolução da Questão A2 apresentada pelo aluno 38

Essa questão teve grande quantidade de acertos (GRÁFICO 2), sendo que apenas sete alunos não tiveram êxito no desenvolvimento do problema. Um dos erros foi classificado na categoria 2, devido a falta de atenção na leitura do problema, fazendo a interpretação de forma incorreta. Os outros seis foram classificados na categoria 5, em que marcaram uma das alternativas sem descrever o raciocínio utilizado. 


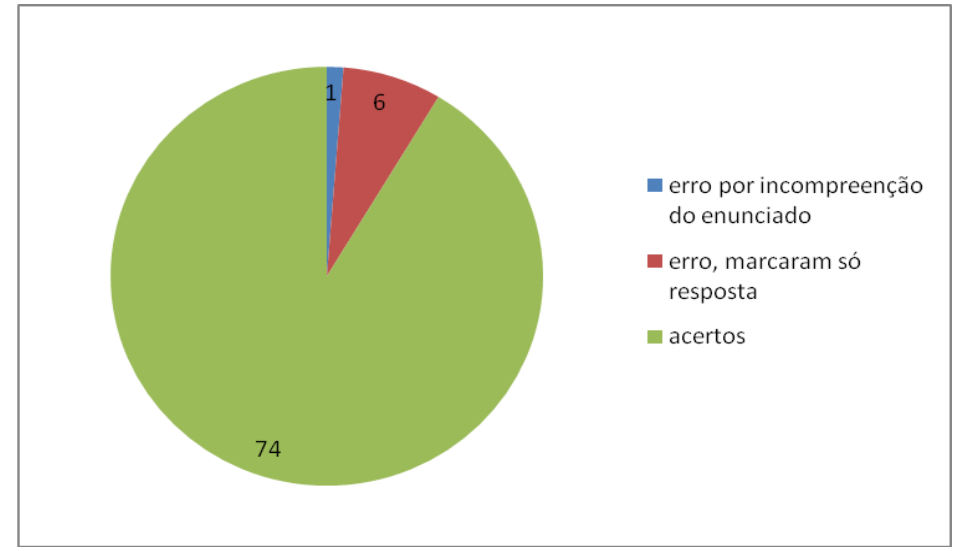

Gráficos 2: Erros e acertos dos alunos da questão A2

Analisando o Gráfico 2, nota-se que a quantidade de alunos que acertaram foi elevada. O baixo índice de erros é um ponto positivo nessa questão, entretanto, a mesma é considerada acessível por ser de interpretação gráfica, sem a necessidade de realizar cálculo.

Para a segunda intervenção, inicialmente, devolveu-se aos alunos as questões do primeiro encontro e fez-se a correção e socialização das ideias que iam sendo construídas ao longo das discussões, buscando sanar suas principais dificuldades e verificar as estratégias utilizadas que foram socializadas com a turma. Cabe destacar que a cada novo encontro era enfatizado aos alunos que demonstrassem em cada questão o raciocínio ou cálculo utilizado para chegar a resposta, mas muitos não conseguiam fazê-lo. Para dar continuidade, apresentou-se um segundo questionário, para resolverem. Este continha três questões retiradas das avaliações externas já mencionadas. Deste, percebeu-se maior motivação dos alunos para respondê-lo. Na sequência, estão as questões B1, B2 e B3 trabalhadas neste encontro e uma das resoluções apresentadas.

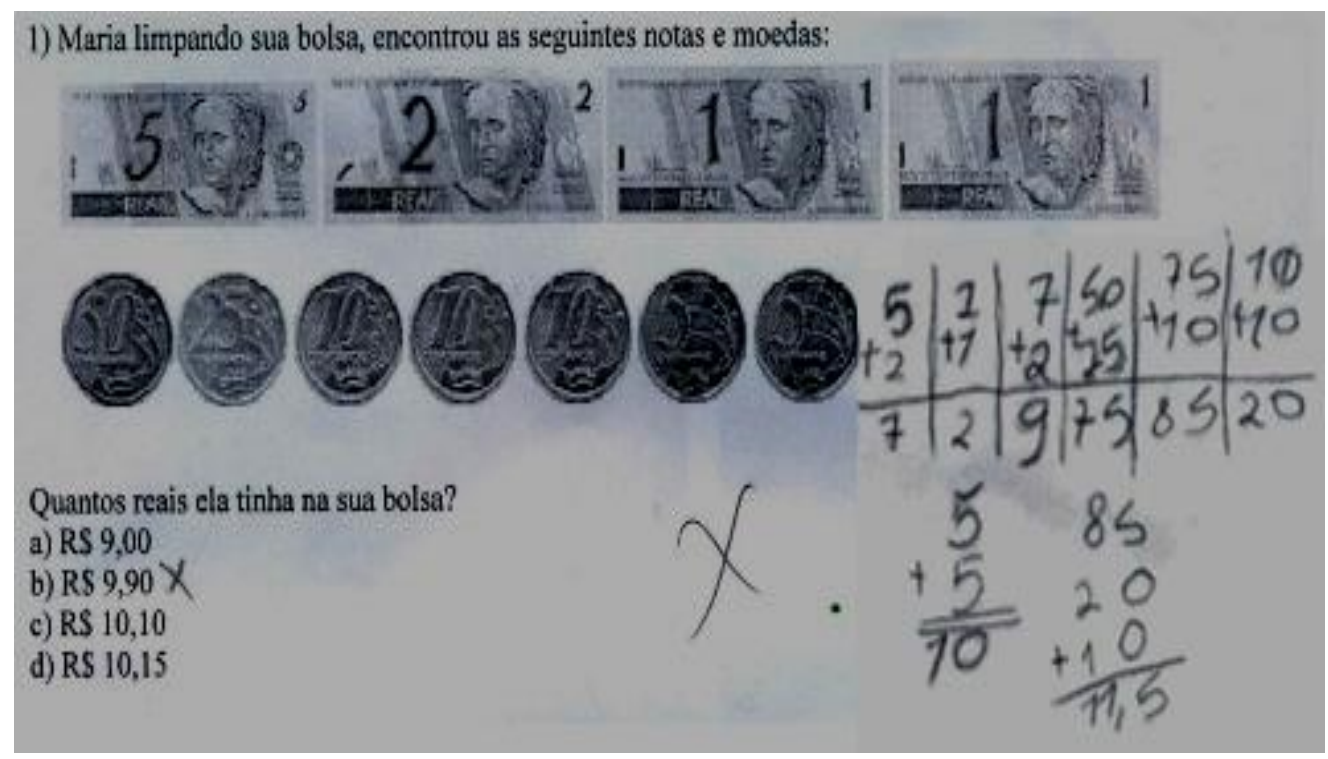

Figura 3: Resolução da Questão B1 apresentada pelo aluno 34

Nessa questão quinze alunos cometeram erro. Dois deles foram classificados na categoria 4, esta que associa os erros cometidos a distração e falta de flexibilidade do pensamento, em que o aluno fez corretamente um plano de resolução mas, para finalizar 
esqueceu de somar o valor das cédulas com o somatório das moedas. Além disso, percebese dificuldade em posicionar corretamente a vírgula no número decimal, colocando-a na casa decimal errada, com isso, não encontra a alternativa que condiz com o resultado que encontrou, assim marcando qualquer opção disponível no problema. Os outros treze, foram incluídos na categoria 5, pois apenas marcaram uma alternativa como resposta.

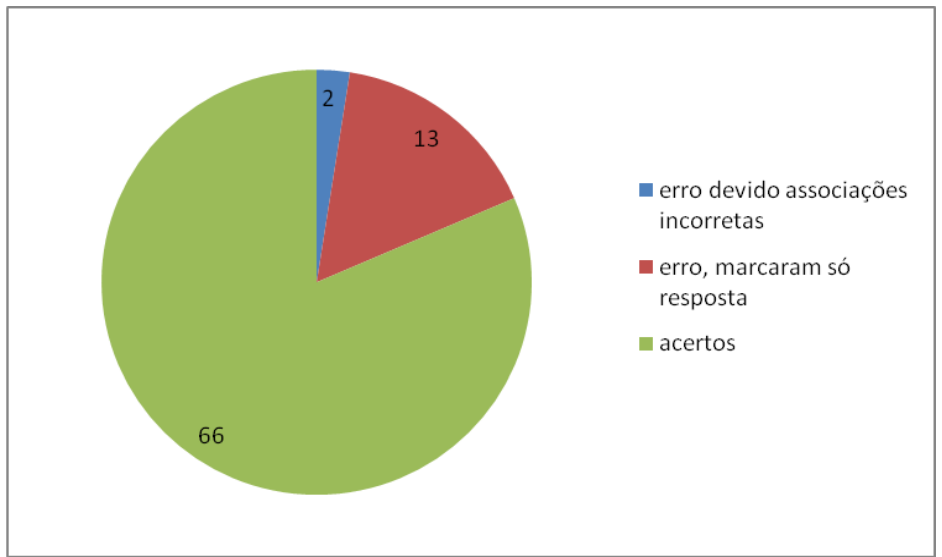

Gráfico 3: Erros e acertos dos alunos da questão B1

O Gráfico 3 mostra o número de erros e acertos cometidos referente à questão anterior. A baixa ocorrência de erros permite entender que os alunos possuem um maior domínio do conteúdo exigido para solucionar a questão. Já os que erraram, tiveram descuido ao interpretar o problema e aplicaram operações incorretas.

A segunda questão proposta envolvia análise de um gráfico a partir de uma situação real.

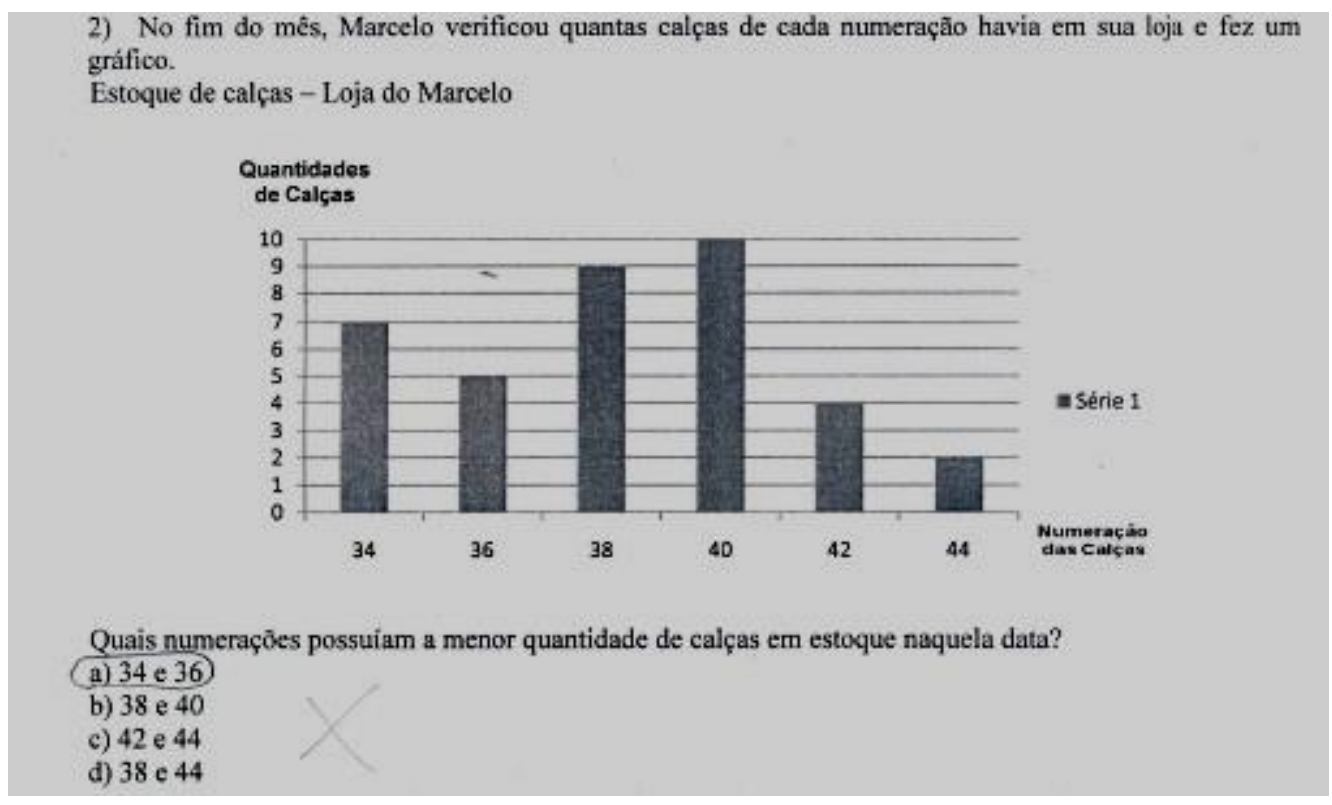

Figura 4: Questão B2

Esta foi a única questão na qual todos os alunos que erraram foram enquadrados na categoria 5, pois marcaram apenas uma alternativa sem justificar ou fazer qualquer tipo de anotação. 


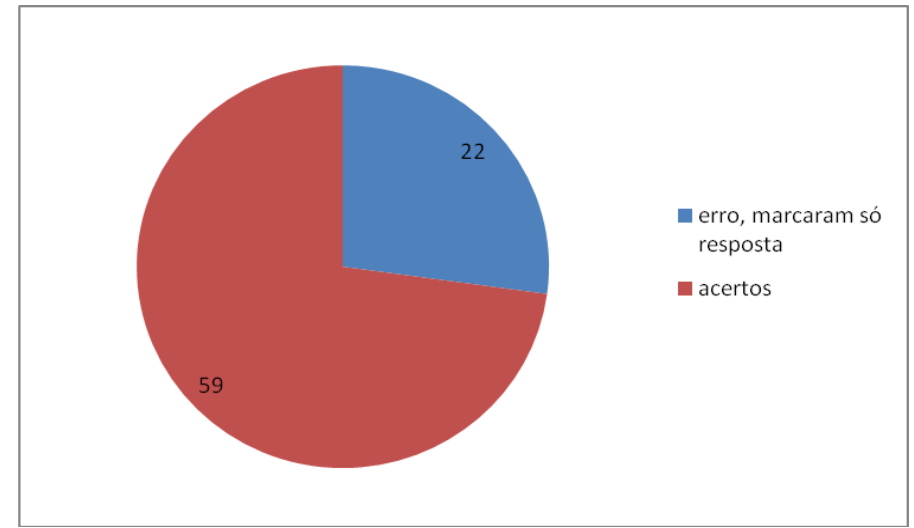

Gráfico 4: Erros e acertos dos alunos da questão B2

Analisando o Gráfico 4, nota-se que nessa questão o número de acertos é bem maior que o de erros. No entanto, por não foram evidenciados os motivos pelos quais cometeram os erros, dificultando uma avaliação para buscar alternativas de aprimorar os conhecimentos dos alunos.

A terceira e última questão desse encontro relacionava a idade ao ano de nascimento, na Figura 5, apresenta-se a questão e a resolução proposta por um dos alunos.

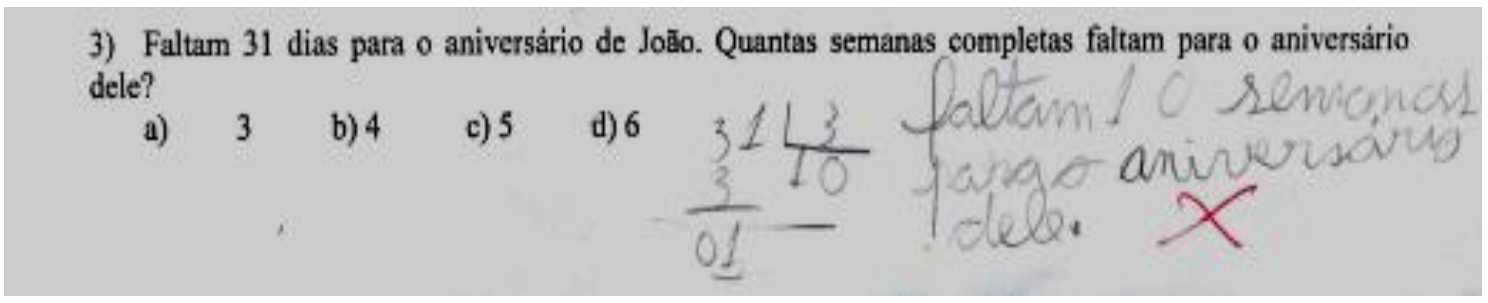

Figura 5: Resolução da questão B3 pelo aluno 26

O Gráfico 5 mostra um elevado número de erros. Mais da metade dos alunos não conseguiram solucionar essa questão. Do total de quarenta e três alunos que cometeram algum erro na resolução, apenas um argumentou o raciocínio utilizado para respondê-la, este sendo enquadrado na categoria 2, pois ele não interpretou corretamente o enunciado e efetuou um cálculo qualquer que não condiz com o que é proposto. Portanto, a resposta na qual chegou, não estava disponível entre as alternativas, assim não marcou nenhuma opção. Os demais foram enquadrados na categoria 5, pois apenas marcaram qualquer alternativa, impossibilitando verificar o que os levou ao erro.

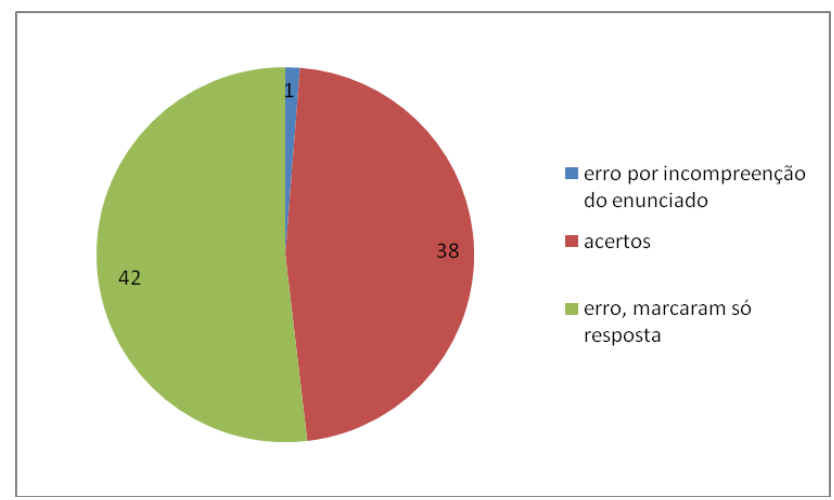

Gráfico 5: Erros e acertos dos alunos na questão B3 
No terceiro e último encontro descrito, devolveu-se o questionário corrigido, aos alunos, referente a intervenção anterior, sendo exploradas as diferentes ideias que os alunos tinham a respeito da resolução de cada questão, enfatizando os principais erros cometidos. Para dar sequência ao terceiro encontro se propôs mais três problemas para solucionarem. As questões C1, C2 e C3, estão demonstradas na sequência, com a resolução apresentada pelos alunos 44, 37 e 11 respectivamente.

1) Roberto correu a Maratona da Pampulha em 2008. Ele fez o percurso em 1 bora e 47 minutos. Qual foi o tempo em minutos gasto por Roberto para completar essa maratona?

a) 100 minutos.

b) 107 minutos.

c) 117 minutos.

147 minulos.
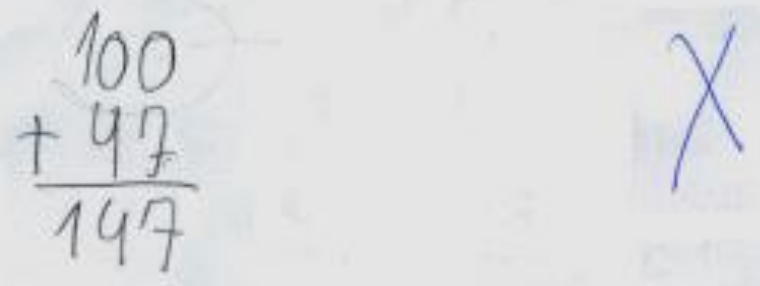

Figura 6: Resolução da questão C1 pelo aluno 44

Nessa questão, quinze alunos cometeram erros. Nove deles se enquadraram na categoria 3, na qual os alunos fizeram a operação correta, mas relacionaram de forma incorreta o tempo de uma hora como sendo 100 minutos e não 60 minutos, isso pode estar relacionado a falta de atenção ou esquecimento. Os demais marcaram apenas uma alternativa como resposta, se enquadrando na categoria 5.

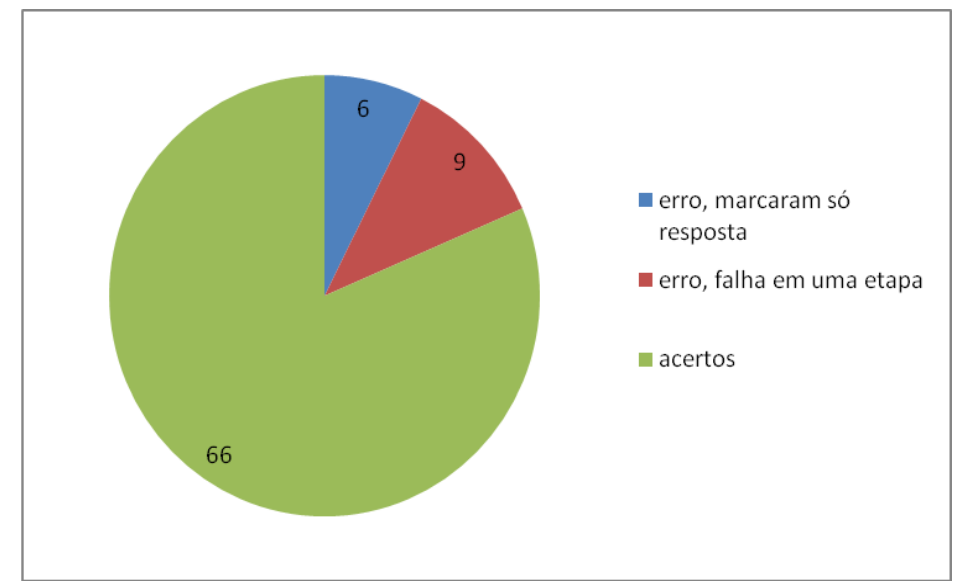

Gráfico 6: Erros e acertos dos alunos na questão C1

O Gráfico 6 evidencia que é significativo o número de alunos que apenas marcaram uma alternativa como resposta, comparado ao número de alunos que apesar de ter compreendido o que o problema exigia e organizado corretamente as operações, cometeram algum erro em uma etapa da resolução. O número de acertos nessa questão é um ponto positivo a ser levado em conta.

A segunda questão apresentada na Figura 7 envolve dinheiro, fato presente na rotina dos alunos. 
2) No més passado, a conta de luz da casa de Pedro foi de R\$ 76,35. Neste més, sua conta de luz foi de RS 67,45. Quanto Pedro pagou a meros de um més pari outro?

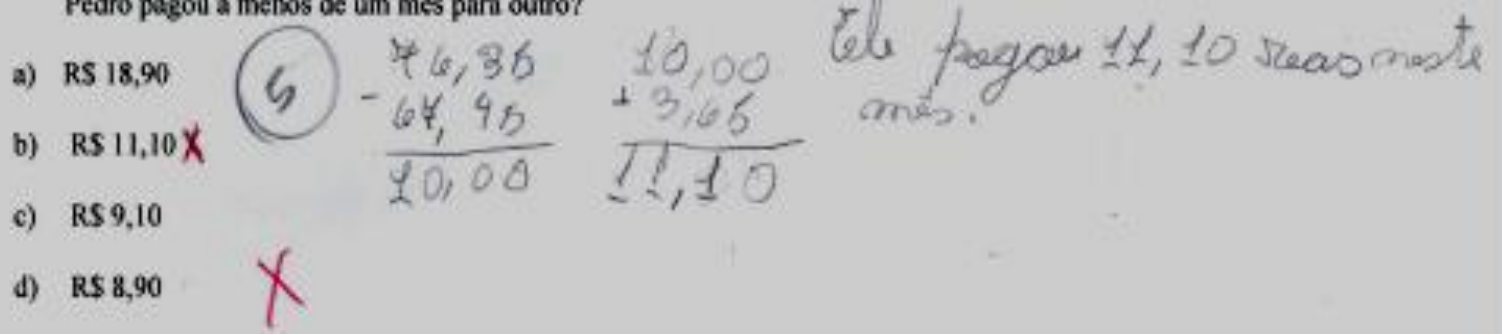

Figura 7: Resolução da questão C2 apresentada pelo aluno 37

Os sete alunos que erraram essa questão se enquadraram na categoria 4 pois fizeram operações incorretas com dados contidos no problema. A resolução do aluno 37 demonstra que fez inicialmente um plano correto, no entanto não soube subtrair a operação corretamente, neste foi observado uma lacuna quando o número a ser subtraído era maior. Assim, o aluno considerava a situação como sendo impossível e do contrário ele fazia a operação corretamente. Por exemplo, quando fez 3 menos 4, atribuiu resultado zero. Como não chegou a nenhuma das alternativas, prosseguiu fazendo cálculos com dados não contidos no problema almejando chegar a alguma das alternativas.

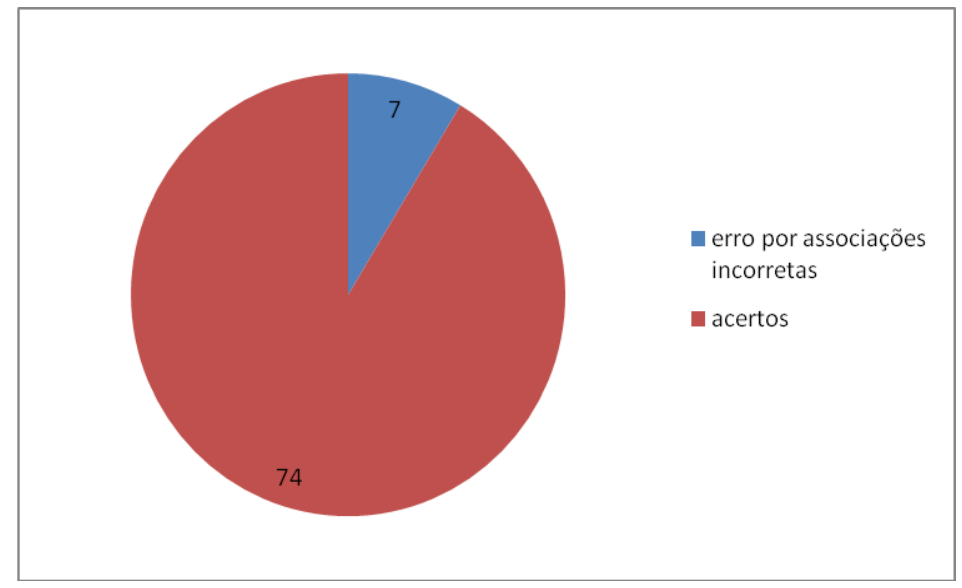

Gráfico 7: Erros e acertos dos alunos na questão C2

Observando o Gráfico 7, percebe-se que a maioria dos alunos acertou essa questão. Os erros foram apenas sete e se encaixaram na mesma categoria. O número alto de acertos e o fato de nenhum aluno ter errado por apenas marcar resposta nos indica que possuem as habilidades necessárias para resolver a questão.

A última questão abordada, apresentada na Figura 8, trata de uma situação de localização espacial. 
3) Marcela fez a seguinte planta da sua sala de aula:

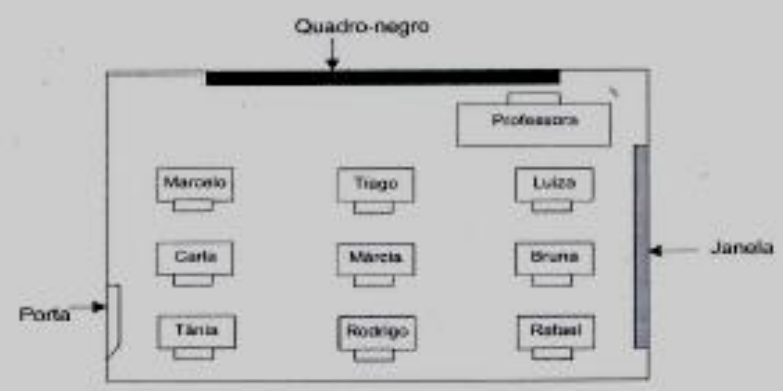

Das crianças que se sentam perto da janela, a que senta mais longe da professora é:

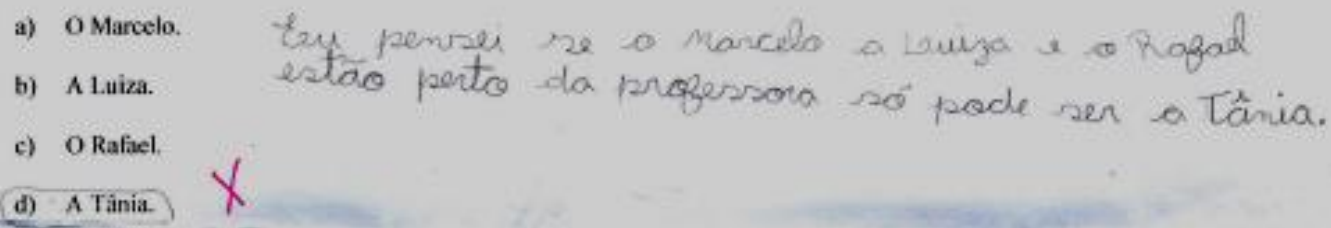

Figura 8: Resolução da questão C3 apresentada pelo aluno 11

Treze alunos erraram essa questão. Quatro deles foram enquadrados na categoria 4, pois não interpretaram na íntegra qual era a pergunta do problema, uma vez que, haviam dois fatores a serem considerados para solucioná-la, e levaram em conta apenas a distância. Os demais foram enquadrados na categoria 5, pois marcaram uma das alternativas sem esclarecer o raciocínio empregado para chegar a sua opção. Porém acredita-se que não devem ter feito uma leitura detalhada do enunciado do problema, uma vez que a mesma exigia apenas interpretação, sem necessidade de cálculo.

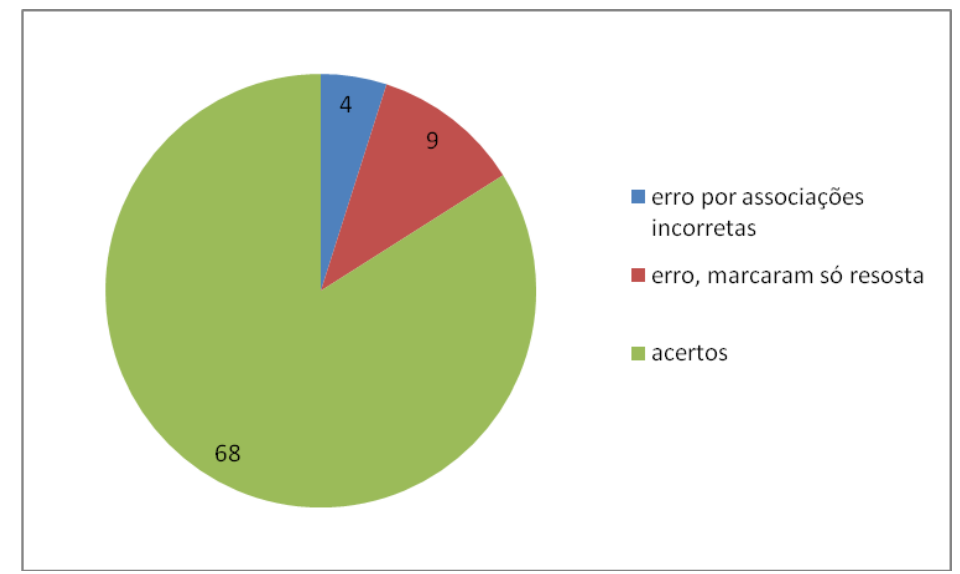

Gráfico 8: Erros e acertos dos alunos na questão C3

O Gráfico 8 mostra que houve pequena quantidade de erros. A maioria deles foram devido a associações incorretas, em que os alunos marcaram qualquer alternativa. 


\section{Considerações}

Foi bastante significativo trabalhar a resolução de problemas como estratégia de ensino de Matemática, já que permitiu aos alunos aprenderem não apenas conhecimentos matemáticos, mas conhecer diferentes meios para solucionar problemas, levando-os a refletir sobre seus erros e aprendendo com estes. Cabe destacar que os alunos ao se depararem com os problemas retirados das avaliações externas já mencionadas, perceberam que o grau de dificuldade era menor que o esperado, e que em muitos casos não era preciso nem fazer cálculos, sendo necessária somente leitura, interpretação e raciocínio lógico. Assim, não sendo preciso lembrar regras prontas ou conteúdos específicos e sim, criar estratégias próprias.

Destaca-se que a cada novo encontro os alunos iam se mostrando mais atentos e interessados em realizar o que estava sendo proposto. Para estimular isso no aluno é importante que o professor crie um ambiente desafiador, tornando a Matemática uma disciplina dinâmica. Com este tipo de trabalho foi possível diagnosticar as dificuldades dos alunos e intervir na construção de sua aprendizagem.

A socialização das diferentes estratégias de resolução utilizadas pelos alunos foi a etapa mais significativa das intervenções, pois eram instigados a se expressar, arriscar mais e a expor suas ideias a respeito do que ia sendo trabalhado. Pois suas interpretações iniciais eram discutidas coletivamente, com isso também foram percebendo que o erro pode ser algo positivo, fazendo parte da aprendizagem.

Verificou-se que a maioria dos estudantes das cinco turmas atendidas obteve êxito na resolução dos problemas propostos, e os principais erros apresentados estavam relacionados à dificuldade de interpretação "muitas vezes, a dificuldade não está na matemática, mas em compreender o enunciado de um problema" (ALVARENGA, ANDRADE e SANTOS, 2016, p. 34). Outro aspecto importante a ressaltar é o fato das questões serem de múltipla escolha e muitos dos alunos apenas terem marcado uma das alternativas como resposta, sem apresentar o raciocínio utilizado, o que não permitiu identificar suas dificuldades e categorizar determinados erros. Silveira corrobora com isso, mencionando que "[...] muitas perguntas ainda continuam sem respostas. Por que as pessoas que fazem cálculos matemáticos com muita eficiência não conseguem colocar no papel os seus "malabarismos" mentais?"(SILVEIRA, 2006, p. 2)".

Espera-se com este trabalho, ter auxiliado os alunos no processo de resolução de problemas e no uso de diferentes estratégias de resolução, bem como fazê-los perceber que o erro pode ser algo produtivo na construção do conhecimento. Enfim, considera-se que analisar os erros cometidos pelos alunos e intervir sobre estes, foi fundamental para terem maior confiança na realização dos problemas, minimizando lacunas na aprendizagem e favorecendo para uma formação mais qualificada. Esta pesquisa possibilita ao professor refletir sobre as práticas em sala de aula, além de contribuir para formação inicial dos futuros profissionais que estiveram envolvidas nessa pesquisa. 


\section{Referências}

ALVARENGA, Karly Barbosa; ANDRADE, Iris Danúbia e SANTOS, Ricardo de Jesus. Dificuldades na resolução de problemas básicos de matemática: um estudo de caso do agreste sergipano. Amazônia - Revista de Educação em Ciências e Matemática. v.12, n.24, 2016. p.39-52.

ASTOLFI, Jean Pierre. El "Error”, um médio para enseñar. Servilla: Díada, 1999.

BRASIL. Parâmetros Curriculares Nacionais +: Ciências da Natureza, Matemática e suas Tecnologias. Ensino Médio. Orientações Educacionais Complementares aos Parâmetros Curriculares Nacionais, Brasília. MEC/SEM, 2002.

BRASIL. SECRETARIA DE EDUCAÇÃO FUNDAMENTAL. Parâmetros Curriculares Nacionais: Matemática, Secretaria de Educação Fundamental. Brasília. MEC/SEF, 1998.

BRASIL. Ministério da Educação. PDE: Plano de Desenvolvimento da Educação: Prova Brasil: Ensino Fundamental: matrizes de referência, tópicos e descritores. Brasília: MEC/SEB, 2008.

CURY, Helena Noronha. Análise de erros: o que podemos aprender com as respostas dos alunos. Belo Horizonte: Autêntica, 2008.

DANTE, Luiz Roberto. Didática da resolução de problemas de matemática. São Paulo: Ática, 1998.

DAVIS, Claudia ; ESPÓSITO, Yara L. Algumas considerações sobre a teoria psicogenética na escola. Idéias, v. 8, 1990. p.127-132.

DULLIUS, Maria Madalena; FURLANETTO, Virginia; QUARTIERI, Marli Terezinha. Análise e classificação dos erros na resolução de uma prova de olimpíada matemática. Anais del VI encuentro Iberoamericano de Colectivos Escolares y Redes de Maestras y Maestros que hacen Investigación e Innovación desde la Escuela. Córdoba, v. Único, 2011. p.1-11.

LIBÂNEO, José Carlos. Didática. São Paulo: Cortez, 1994.

ONUCHIC, Lourdes de la Rosa. Ensino - Aprendizagem de Matemática através da Resolução de Problemas. In: BICUDO, Maria Aparecida Viggiani (org.) Pesquisa em educação Matemática: Concepções \& Perspectivas. São Paulo: UNESP, (p. 199-218), 1999.

RADATZ, Hendrik. Error Analysis in Mathematics Education. Journal for Research in Mathematics Education, v.10, n.2, 1979. p.163-172.

SILVEIRA, Marisa Rosane Abreu da. A crítica ao ensino da matemática. Amazônia - Revista de Educação em Ciências e Matemática, v.2, n.3, 2006. p.1-7.

SMOLE, Kátia Stocco; DINIZ, Maria Ignez. Ler, escrever e resolver problemas: habilidades básicas para aprender matemática. Porto Alegre: Artmed, 2001. 